University of Wollongong

Research Online

Faculty of Engineering and Information

Faculty of Engineering and Information

Sciences - Papers: Part B

Sciences

2017

\title{
Lithium extraction from Chinese salt-lake brines: opportunities, challenges, and future outlook
}

Jianfeng Song

University of Chinese Academy of Sciences, Chinese Academy Of Sciences

Long D. Nghiem

University of Wollongong, longn@uow.edu.au

Xuemei Li

Chinese Academy Of Sciences

Tao He

Chinese Academy Of Sciences, het@sari.ac.cn

Follow this and additional works at: https://ro.uow.edu.au/eispapers1

Part of the Engineering Commons, and the Science and Technology Studies Commons

Research Online is the open access institutional repository for the University of Wollongong. For further information contact the UOW Library: research-pubs@uow.edu.au 


\title{
Lithium extraction from Chinese salt-lake brines: opportunities, challenges, and future outlook
}

\author{
Abstract \\ Chinese salt-lake brine is mainly of the magnesium sulfate subtype with a high $\mathrm{Mg} / \mathrm{Li}$ ratio. Mining lithium \\ from Chinese salt-lake brine has been a decades-long technical challenge. The pros and cons of various \\ technologies are briefly discussed. Chemical extraction has been the most important technology for the \\ recovery of lithium from Chinese salt-lake brine with a high $\mathrm{Mg} / \mathrm{Li}$ ratio. Several other innovative \\ technologies, including lithium ion sieves, membrane separation, and electro-electrodialysis, have also \\ emerged as potential options. \\ Disciplines \\ Engineering | Science and Technology Studies

\section{Publication Details} \\ Song, J., Nghiem, L. D., Li, X. \& He, T. (2017). Lithium extraction from Chinese salt-lake brines: \\ opportunities, challenges, and future outlook. Environmental Science: Water Research and Technology, 3 \\ (4), 593-597.
}




\title{
Environmental Science: Water Research and Technology
}

\section{Perspective}

\section{Lithium extraction from Chinese salt-lake brines: opportunities, challenges, and future outlooks}

Received 00th January 20xx, Accepted 00th January 20xx

DOI: $10.1039 / x 0 x x 00000 x$

www.rsc.org/

\begin{abstract}
Jian Feng Song ${ }^{\mathrm{a}, \mathrm{b}}$, Long D. Nghiem ${ }^{\mathrm{c}}$, Xue-Mei Li ${ }^{\mathrm{a}}$ and Tao $\mathrm{He}^{\mathrm{a}}$
Chinese salt lake brine is mainly of magnesium sulfate subtype with a high $\mathrm{Mg} / \mathrm{Li}$ ratio. Mining lithium from Chinese salt lake brine has been decades-long technical challenge. The Pros-and-Cons of various technologies were briefly discussed. Novel redox battery based technolges were introduced. Chemical extraction based on column or membrane contactor has been the most widely used technology for the recovery of Lithium from salt lake brine. Several other innovative technologies including Lithium ion sieve, membrane separation, and electro-electrodialysis have also emerged as potential options for the extraction of lithium from salt lake brines with a high $\mathrm{Mg} / \mathrm{Li}$ ratio.
\end{abstract}

\section{Introduction}

Lithium, the lightest metallic element, is one of the most important commodities because of its wide applications in nuclear fusion (where lithium isotopes are required as heat conveyance media) [2] and particularly rechargeable lithium ion batteries [1]. The rapid expansion of the electric vehicles (EVs) [3] and grid energy storage [4] markets places a strong demand for lithium from the battery industry. The price of lithium carbonate has been more than tripled since 2015 to $129,000 \mathrm{RMB} / \mathrm{t}$ as at December 2016 [5]. As a result, the demand for lithium has been dramatically increased in recent years $[6,7]$.

Lithium can be obtained from seawater, Li-containing ores, and lithium rich salt-lake brines. Despite the large lithium reservation in the ocean of about 231.4 trillion tonnes, lithium recovery from seawater is not yet economically viable because of the low concentration in seawater of around $0.178 \mathrm{mg} / \mathrm{L}$ [8]. There are other major lithium sources namely Li-containing ores (e.g.: spodumene, petalite and lepidolite) and salt lake brines. The latter account for over $80 \%$ of total recoverable lithium deposit [9]. There is a clear trend for the lithium industry to shift from ores to salt lake brines [10] as lithiumrich ore reserve is diminished and cost-effective technologies for lithium production from salt lake brines starts to emerge [3]. Lithium concentration in salt lake brine varies from site to site, however, in most cases, it is much higher than that in seawater as demonstrated in Table 1 which summarises lithium concentration in several Chinese salt lakes.

\section{Chinese salt lake brine}

\footnotetext{
Laboratory for Membrane Materials and Separation Technology, Shangha Advanced Research Institute, Chinese Academy of Sciences, Shanghai 201203, China.

${ }^{b}$. University of Chinese Academy of Sciences, Beijing, 100049, China.

Strategic Water Infrastructure Laboratory, School of Civil, Mining and Environmental Engineering, University of Wollongong, Wollongong, NSW 2522, Australia.
}

In China, lithium-rich salt lakes are located mostly in the Qinghai Tibet Plateau. This region is known for its significant lithium resource. Lithium deposit in the Qinghai provinces was estimated to be about 244.7 Mt [11]. The enriched source of lithium in those brine was relative to the geothermal activity related from volcanic systems [12] and anatectic magmatism [13]. The volcanic hot water from the area between the middle and southern Kunlun faults was an important source of potassium, boron, and lithium in the Qarhan salt lake. Based on the location of brine in salt lake, the natural brine can be classified into surface, intergranular, over-saturated brine [13]. The last two types can be used for mineral extraction and further classified into original brine, brine after precipitation of sodium salt, brine after crystalline potassium salt, and concentrated brine (Fig. 1). As an example, for the East Taijinar salt lake, the concentration of lithium increased sequentially to reach $4-5 \mathrm{~g} / \mathrm{L}$ in the concentrated brine (Fig.1).

Table 1 Lithium ion concentration in the Chinese salt lakes

\begin{tabular}{|c|c|c|c|c|}
\hline \multirow{2}{*}{ Salt lake } & \multicolumn{2}{|c|}{ Conc. g/L } & \multirow{2}{*}{ Deposit $^{\mathrm{a}}$ / Mt } & \multirow{2}{*}{ Ref. } \\
\hline & $\mathrm{Li}$ & $\mathrm{Mg}$ & & \\
\hline West Taijinar & $0.25-6.70$ & $12.80-92.43$ & 2.68 & [14-16] \\
\hline East Taijinar & 0.14 & 22.20 & 2.47 & {$[14,16]$} \\
\hline Qarhan & $0.21-0.35$ & $66.5-115.0$ & 7.17 & {$[17]$} \\
\hline Zabuye & $0.42-1.61$ & 0.01 & $1.84-7.90$ & [18] \\
\hline Dangxiongcuo & $0.30-1.60$ & $<1.0$ & $0.86-0.95$ & [19] \\
\hline Yiliping & $0.13-2.2$ & 17.36 & $1.78-99.1$ & {$[11,20]$} \\
\hline Da Qaidam & $0.1-1.30$ & $9.0-117.0$ & 2.00 & [11] \\
\hline Jiezecaka & 0.56 & 0.40 & 2.30 & [21] \\
\hline Longmucuo & 1.21 & 89.5 & 2.17 & {$[21]$} \\
\hline
\end{tabular}

a: Reference $[10,11,22]$ 


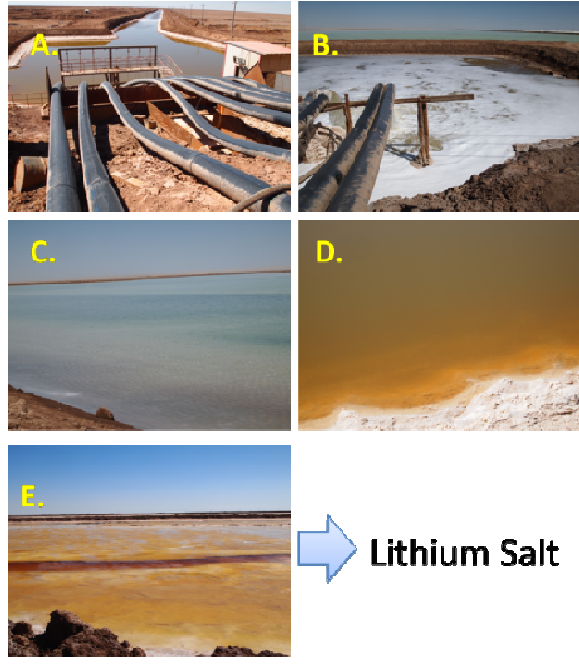

Fig.1. The sequential evaporation pond for the enrichment of lithium at East Taijinar salt-lake brine. The intergranular brine was pumped from underground basin to a trench (A); Brine was further distributed via a reservoir (B); Evaporation by solar power to precipitate sodium chloride (C); the brine after production of potassium chloride, at this stage the lithium concentration was about $2 \mathrm{~g} / \mathrm{L}$ (D); Further evaporation of the brine enriched the lithium concentration up to 4-5 $\mathrm{g} / \mathrm{L}(\mathrm{E})$; Finally, The concentrated brine was used for the lithium recovery.

Based on the Kurnakov-Valyashko classification, salt lakes can be divided into the chloride type, sulfate type (with magnesium sulfate and sodium sulfate subtype), and carbonate type [23]. Carbonate-rich lakes are located in the southern and south western part of the plateau, and magnesium/sulfate-rich lakes are in the Qaidam Basin, in the northern part of the plateau [13].

The most important lithium-bearing deposit in the zone of carbonate-type lakes is Zabuye Lake. Because of very low magnesium concentrations (Zabuye and Jezecaka Lake in Table 1), production of lithium from these lakes can be readily achieved. Lithium carbonate can be precipitated directly from the brine by evaporation. This is similar to the process currently used to extract lithium from the Silver Peak Lake in the US and Atacama Lake in Chile [24]. The $\mathrm{Mg} / \mathrm{Li}$ ratios in brine from Silver Peak and Atacama Lake are only 2 and 0.1-1, respectively.

\section{Lithium recovery from brine of high $\mathrm{Mg} / \mathrm{Li}$ ratio}

Most salt lake brines in China are magnesium sulfate subtype and the ratio of $\mathrm{Mg} / \mathrm{Li}$ can be as high as 50 , and in some cases up to 500 (Table 1) [16, 18]. The chemical precipitation approach that has been successfully applied for low calcium and magnesium brines (such as those from Zabuye and Jezecaka Lake) would consume a large quantity of chemicals and generate a huge amount of solid waste [25]. In addition, lithium loss due to co-precipitated and adsorption to calcium/magnesium precipitate is also significant.
Table 2 State-of-the-art of the technologies of recovery lithium from

salt-brine in China

\begin{tabular}{|c|c|}
\hline Technology & Status and pros and cons \\
\hline Calcination & $\begin{array}{l}\text { - The brine is sprayed dry to get the solid } \\
\text { mixture of } \mathrm{MgCl}_{2} * 2 \mathrm{H}_{2} \mathrm{O} \text { and } \mathrm{LiCl} \text {. After carbonated } \\
\text { to } \mathrm{MgO} \text { and } \mathrm{LiCl} \text { in rotary kiln at } 800-100{ }^{\circ} \mathrm{C} \text {, the } \\
\mathrm{LiCl} \text { was dissolved because the solubility of } \mathrm{MgO} \text { is } \\
\text { low; } \mathrm{LiCl} \text { is then precipitated to } \mathrm{Li}_{2} \mathrm{CO}_{3} \text {. } \\
\text { - } 10,000 \text { t/y pilot in East Taijinar; but stopped } \\
\text { - Mature technology but high energy cost; } \\
\text { - air pollution due to emission of acid mist }\end{array}$ \\
\hline Adsorption & $\begin{array}{l}\text { - Lithium ion sieve: lithium ion selective sieves } \\
\text { can selectively absorb } \mathrm{Li}+\text { from brine; then } \mathrm{Li}+\text { are } \\
\text { desorbed by dilute } \mathrm{HCl} \text { solution to obtain lithium } \\
\text { rich solution } \\
\text { - } 10,000 \mathrm{t} / \mathrm{y} \text { in Qarhan installed in 2007; not yet } \\
\text { in full scale operation. } \\
\text { - Low cost and easy to larger scale; } \\
\text { - Dissolution of adsorbent; } \\
\text { - Reduced adsorbing capacity due to blockage of } \\
\text { the ion channels }\end{array}$ \\
\hline \multirow{3}{*}{ Extraction } & $\begin{array}{l}\text { Organic extractants are able to selectively extract } \\
\text { Li+ from brine; theoretical basis is known; } \\
\text { however, suitable extracting equipment with small } \\
\text { footprint, low cost, high efficiency is required. }\end{array}$ \\
\hline & $\begin{array}{l}\text { Mixer-settler } \\
\text { - } 1000 \text { t/y in Da Qaidam; } \\
\text { - } \quad \text { Low cost and easy to larger scale; } \\
\text { - Large volume, footprint, long equilibrium time, } \\
\text { auto control difficult; }\end{array}$ \\
\hline & $\begin{array}{l}\text { Centrifuge } \\
\text { - } \quad \text { pilot in East Taijina; } 1000 \mathrm{t} / \mathrm{y} \\
\text { - } \quad \text { High efficient, short equipment time; } \\
\text { - } \quad \text { High CAPEX; very difficult to realize large scale }\end{array}$ \\
\hline Membrane & $\begin{array}{l}\text { - Electrodialysis: Monovalent and divalent } \\
\text { cations diffuse at different speed in electric field } \\
\text { across the ion exchange membrane; separation } \\
\text { occurs for } \mathrm{Li}^{+} \text {and } \mathrm{Mg}^{2+} \\
\text { - Project of } 10,000 \mathrm{t} / \mathrm{y} \text { in East Taijinar; not yet } \\
\text { full scale operation; } \\
\text { - Nanofiltration (NF) membrane separates } \\
\text { monovalent ions and divalent ions; thus is able to } \\
\text { separate } \mathrm{Mg}^{2+} \text { from } \mathrm{Li}^{+} \text {; the brine has to be diluted } \\
\text { to reduce osmotic pressure } \\
\text { - failed in pilot stage; NF process can separate } \\
\text { the monovalent and divalent salt, and the same to } \\
\mathrm{Li}^{+} \text {and } \mathrm{Mg}^{2+} \text {, but } \\
\text { - Easy to control and low energy consumption; } \\
\text { - Emerging technology; not commercial } \\
\text { membrane system available; Potential membrane } \\
\text { fooling/scaling; }\end{array}$ \\
\hline
\end{tabular}

The technologies to extract lithium from brine with high $\mathrm{Mg} / \mathrm{Li}$ ratio include calcination, adsorption, extraction and membrane separation $[25,27]$ (Table 2). These technologies have been explored for potential large scale production. however, most of these technologies are still at a piloting stage or small scale production. A project for $10,000 \mathrm{t} / \mathrm{y} \mathrm{Li}_{2} \mathrm{CO}_{3}$ was implemented using calcination technology from East Taijinar salt lake [28], but has not yet reached the target operation due to high energy cost and emission of acid mist which corroded the equipment and severe air pollution. Adsorption using lithium ion selective sieve was claimed reach commercialisation (capacity of $10,000 \mathrm{t} / \mathrm{y}$ ) in 2007 . However, 
until now, the project has not yet achieved full scale operation due to several undisclosed technical issues. Nanofiltration and electrodialysis membranes have also been investigated for lithium recovery from salt lake brine over the last decade. The separation of magnesium and lithium by either nanofiltration or electrodialysis is technically challenging given their very similar hydrated radius [26]. As a traditional technology, chemical extraction has seen recent resurgence in both research and industry. In the following section, technologies with strong potential will be further discussed.

\section{Lithium ion sieve}

The lithium ion sieve is a specific absorbent with high selectivity for lithium ions. Li-Mn-O ternary oxides have been used to prepare ion sieves for lithium recovery from salt lake brines because the $\mathrm{Li}-\mathrm{Mn}-\mathrm{O}$ frame work can maintain a cubic spinel structure during the $\mathrm{Li}^{+}$insertion and extraction process. These oxides contain a series of chemicals, such as the spinel manganese oxides [29-32], nanostructure $\mathrm{MnO}_{2}$ [33]. Inspired by lithium ion sieve, the titanium lithium ionic and lithium iron phosphate $\left(\mathrm{LiFePO}_{4}\right)$ sieves have also been investigated [3437]. These absorbents have been tested for recovery lithium from brine of Qarhan saline lake [38]. Challenges for ionic sieves include: (1) dissolution of metal ion from the adsorbent together with lithium ions during the acid treatment; (2) splitting of sieve particles into smaller ones; (3) collecting the particles, washing and regenerating processes are still expensive; (4) reduced adsorbing capacity due to blockage of the ion channels. Hence, to improve the performance, the granulation and regeneration of lithium sieve still need further study.

\section{Chemical extraction}

Liquid-liquid extraction has been widely studied for recovering lithium from brine with high ratio of $\mathrm{Mg} / \mathrm{Li}$. $\beta$-diketones and $\mathrm{n}$ butanol was reported as extractant to extract lithium from brine in 1970s [39, 40]. In addition to these studies, neutral organophosphorus extractants [41, 42] have also been investigated. One typical extraction system is tributyl phosphate (TBP)/kerosene- $\mathrm{FeCl}_{3}$. In this system, $\mathrm{FeCl}_{3}$ solution plays the role of a co-extracting agent, which is crucial for extracting ithinim. The mectransism of extra Methyl isobutyl ketone (MME) (465), bis(2-ethylhexyl) acetamide (N523) [47], ionic liquid [48] were has been investigated. Other extractants, N503 [49], N523 [50], di-(2-ethylhexyl) phosphoric acid (D2EHPA) were studies as a single extractant. Of those extractants, TBP is probably the most suitable for the brine of a high $\mathrm{Mg} / \mathrm{Li}$ ratio and pilot-scale extraction process based on this extractant has been studied. Equipment selection has been a major challenge in implementing chemical extraction for Lithium recovery. Mixsettler was selected as the extraction equipment by Qinghai
Institute of Salt Lakes of Chinese Academy of Sciences in the 1990s. Some plants have also used mix-settler for pilot scale production. A typical example is the mix-settler equipment built to recovery lithium form Da Qaidam salt lake in 2016. However, large footprint, large liquid volume, severe corrosion by the extractant and long equilibrium time are still among a few remaining technical issues to be solved. The extractants and extraction processes have been optimised [46, 47], however, selection of suitable equipment is still a technical and scientific challenge.

To reduce the large liquid volume and long equilibrium time, centrifuge system was proposed in a key project from Chinese Academy of Sciences in 2014. Since a large quantity of fluid (organic extractant and brine) are involved in extraction, exceptional large anticorrosive centrifuges were needed; furthermore, low energy efficiency of the centrifuge leads to high energy cost. As a partner in this project, membrane team from Shanghai Advanced Research Institute (SARI) selected different approaches: membrane chemical extraction and reciprocal column (Karr column) extraction.

The potential advantages of membrane extraction techniques are low capital and operating costs, low energy consumption, potentially small footprint (comparing to mix-settler). In a membrane extraction process, a membrane barrier, which is permeable to cations (i.e. $\mathrm{Li}^{+}, \mathrm{Mg}^{2+}, \mathrm{Na}^{+}$) and impermeable to organic extraction, is located at the interface between the organic extractant and brine; lithium ions are selectively extracted and purified. However, solvent stable membrane barrier is required with longtime stability [51-53]. A recent report on solvent stable hydrophilic nanoporous poly (ethy lene-co-vinyl alcohol) membrane [15] showed a stable lithium extraction for 1037 hours. The stable performance indicates the potential of present membrane for large-scale applications. Reciprocal extraction column has been widely used in the petrochemical industrial. The Karr reciprocating plate extraction column with high load capacity will be an effective solution. This equipment is efficient in treating large amount of liquid, small footprint, easy automation, tolerable to liquid with high load of foulant. After thorough analysis and balance of the treatment capacity, energy consumption as well as the risk of separation of organic from brine, we decided to test the column technology. The experimental results proved that former bias on the column was soundless. The high load Karr column was developed to extract lithium form West Taijinar lake brine in our research; the TBP system was selected and new chemical exchange process was used to improve the purity of lithium product. The purity of lithium can be controlled and the highest value was $99.9 \%$ (Fig.2) 


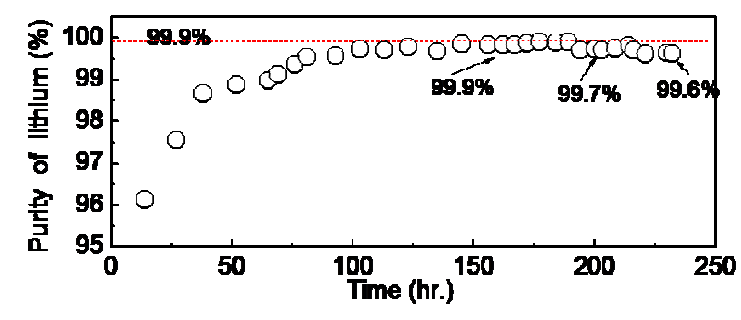

Fig.2. The purity of lithium chloride obtained in a continuous extraction experiment using Karr column and brine from West

Taijinarlake. TBP was used as the extractant. The purity as indicated in the graph corresponds to different adjustment of the process parameters.

\section{Electro chemical process}

Electro-electrodialysis with bipolar membrane (EEDBM) has been investigated as a new method to extract lithium from brines [54]. Discarded rechargeable batteries have been recently used for lithium recovery. The lithium ion capturing electrode behaves as a lithium ion sieve; the process is driven by electricity. Lithium ion is inserted into $\mathrm{FePO}_{4}$ from lithium salt solution during the discharge reaction of Lithium ion phosphate rechargeable battery. Based on this reaction, the battery technology that consists of lithium capturing electrode, the $\mathrm{FePO}_{4}$ anode, and $\mathrm{LiFePO}_{4}$ cathode was studied $[55,56]$. A chloride-capturing electrode $(\mathrm{Ag})[57,58]$ and sodium thiosulfate was found to have an optimum redox potential [59] during the process of lithium recovery. Another ion sieve obtained from spinel phases of lithium manganese oxides (LiMO), such as $\mathrm{LiMn}_{2} \mathrm{O}_{4}$ and $\mathrm{Li}_{1.33} \mathrm{Mn}_{1.67} \mathrm{O}_{4}$, retains the framework of the parent compounds and it is highly selective for lithium in aqueous environments [31, 60]. Spinel $\mathrm{LiMn}_{2} \mathrm{O}_{4}$ (LMO) has been reported as lithium ion sever intercalation electrode and polypyrrole (PPy) reversible chloride electrode [61]. A $\lambda-\mathrm{MnO}_{2}$ positive electrode and a $\mathrm{Ag}$ negative electrode [62] were also investigated. To reduce the cost and increase long term stability, a $\lambda-\mathrm{MnO}_{2} /$ activated carbon hybrid supercapacitor system was studied to recovery lithium form solution [63]. However the redox reactions caused the dissolution of manganese ions and destablize the MnO. Therefore, development of new materials for lithium-ioncapturing electrodes remains an active subject for further study.

\section{Summary and outlook}

Brine has been the most important target for lithium ion extraction for the lithium battery development. Particularly in China, salt-lake brine, mainly of sulfate type, has been the core for lithium recovery. However, the high $\mathrm{Mg} / \mathrm{Li}$ ratio commonly found in most Chinese salt lakes is still a challenge for large scale lithium production. Potential technologies to overcome this challenge include lithium sieve, chemical extraction, nanofiltration, and electro-electrodialysis. Chemical extraction was the most promising approach in the near future. We compared the pros-and-cons of current extraction techniques and equipment including mix-settler, centrifuge, column and membrane contactors. Column extraction technology was a promising technology. Novel extraction technologies driven by electro chemical reaction were introduced; development of new materials for electrodes and long term stability, selectivity are the main challenges for these potential technologies.

\section{Acknowledgements}

The authors thank National Natural Science Foundation of China (U1507117,21676290), TMSR from Chinese Academy of Sciences (XDA02020100), Key Research Fund (CAS2014 Y424541211), and the University of Wollongong from University for financial support and a Vice Chancellor International Visiting Award Fellowship to Tao He.

\section{Notes and references}

1 J.M. Tarascon,M. Armand. Nature, 2001, 414, 359-367.

2 A. Martin, L.L. David, N. Poul Erik, P. Francesca, and V.S. Verne. The Astrophysical Journal, 2006, 644, 229.

3 C. Grosjean, P.H. Miranda, M. Perrin, and P. Poggi. Renewable and Sustainable Energy Reviews, 2012, 16, 17351744.

4 B. Dunn, H. Kamath, and J.M. Tarascon. Science, 2011, 334, 928-35.

5 http://www.100ppi.com/price/detail-3706062.html.

6 P.B. Antonino Salvatore Aricò1, Bruno Scrosati3, Jean-Marie Tarascon4 \& Walter van Schalkwijk5. Nature Materials, 2005, 4, 366 - 377.

7 P.G. Bruce, S.A. Freunberger, L.J. Hardwick, and J.-M. Tarascon. Nature Materials, 2012, 11, 19-29.

8 M.S. Diallo, M.R. Kotte, and M. Cho. Environmental Science \& Technology, 2015, 49, 9390-9399.

9 L. Wang, C.G. Meng, and W. Ma. Colloids and Surfaces A: Physicochemical and Engineering Aspects, 2009, 334, 34-39.

10 S.E. Kesler, P.W. Gruber, P.A. Medina, G.A. Keoleian, M.P. Everson, and T.J. Wallington. Ore Geology Reviews, 2012, 48, 55-69.

11 Z. Li, F. Tang, S. Yang, and C. Ju. World Nonferrous Metal, 2016, 8, 47-49. 
12 Y. Zhu, Z. Li, B. Wu, and M. Wang. Acta Geologica Sinica English Edition, 1990, 3, 247-259.

13 M. Zheng,X. Liu. Aquatic Geochemistry, 2009, 15, 293-320. 14 S.-Y. Sun, L.-J. Cai, X.-Y. Nie, X. Song, and J.-G. Yu. Journal of Water Process Engineering, 2015, 7, 210-217.

15 L. Xing, J. Song, Z. Li, J. Liu, T. Huang, P. Dou, Y. Chen, X.-M. Li, and T. He. Journal of Membrane Science, 2016, 520, 596606.

16 F. Gao, M. Zheng, Z. Nie, J. Liu, and P. Song. Acta Geologica Sinica, 2011, 32, 483-492.

17 W. Xiang, S. Liang, Z. Zhou, W. Qin, and W. Fei. Hydrometallurgy, 2016, 166, 9-15.

18 Z. Nie, L. Bu, and M. Zheng. Acta Geologica Sinica, 2010, 31, 95-101.

19 Q. Wu, M.-P. Zheng, Z. Nie, and L.-Z. Bu. Chinese Journal of Inorganic Chemistry, 2013, 29, 36-44.

20 S. Bi,X. Cui. Inorganic Chemicals Industry, 2016, 48, 27-29.

21 H. Yong, Z. Qihai, L. Guanghan, and Z. Chengcai. Inorganic Chemicals Industry, 2013, 45, 27-29.

222016 , Seminar of Lithium resource (China. Beijing).

23 F. Han. Journal of Salt Lake Research, 2001, 9, 55-61.

24 Z. Nie, L. Bu, M. Zheng, and W. Huang. Solar Energy, 2011,

$85,1537-1542$.

25 B. Swain. Separation and Purification Technology, 2017 172, 388-403.

26 H. Vikström, S. Davidsson, and M. Höök. Applied Energy, $2013,110,252-266$.

27 Z. Yuan, L. Lijuan, W. Zhijian, and L. Xiang. Process in Chemistry, 2013, 25, 1613-1624.

$28 \mathrm{X}$. Wu,H. Zhu. Chemical Industry of Guangdong, $201264+74$.

29 R. Chitrakar, H. Kanoh, Y. Makita, Y. Miyai, and K. Ooi. Journal of Materials Chemistry, 2000, 10, 2325-2329.

30 L. Tian, W. Ma, and M. Han. Chemical Engineering Journal, 2010, 156, 134-140.

31 Q.-H. Zhang, S.-P. Li, S.-Y. Sun, X.-S. Yin, and J.-G. Yu. Chemical Engineering Science, 2010, 65, 169-173.
32 R. Chitrakar, Y. Makita, K. Ooi, and A. Sonoda. Chemistry Letters, 2012, 41, 1647-1649.

33 S. Zandevakili, M. Ranjbar, and M. Ehteshamzadeh. Hydrometallurgy, 2014, 149, 148-152.

34 L. Zhang, D. Zhou, G. He, Q. Yao, F. Wang, and J. Zhou. Materials Letters, 2015, 145, 351-4.

35 R. Chitrakar, Y. Makita, K. Ooi, and A. Sonoda. Dalton Transactions, 2014, 43, 8933-8939.

36 D. Tang, D. Zhou, J. Zhou, P. Zhang, L. Zhang, and Y. Xia. Hydrometallurgy, 2015, 157, 90-96.

37 Z.-w. Zhao, X.-x. Lang, X.-h. Liu, L.-h. He, X.-y. Chen, X.-f. Si, and A.-I. Chen. Chinese Journal of Nonferrous Metals, 2013, 23, 559-67.

38 L. He, R. Chen, Y. Xu, and B. Cai. Hydrometallurgy of China, 2003, 22, 118-128.

39 F.G. Seeley,W.H. Baldwin. Journal of Inorganic and Nuclear Chemistry, 1976, 38, 1049-1052.

40 G.G. Gabra,A.E. Torma. Hydrometallurgy, 1978, 3, 23-33.

41 H. Bukowsky, E. Uhlemann, K. Gloe, and P. Mühl. Hydrometallurgy, 1992, 28, 323-329.

42 X.-I. Sun, B.-z. Chen, H. Xu, and X.-c. Shi. Journal of Central South University (Science and Technology), 2007, 38.

43 Z. Zhou, W. Qin, and W. Fei. Journal of Chemical \& Engineering Data, 2011, 56, 3518-3522.

44 Z. Zhou, W. Qin, Y. Liu, and W. Fei. Journal of Chemical and Engineering Data, 2012, 57, 82-86.

45 Y. Zhang, L. Li, J. Li, L. Ji, Q. Xu, and G. Chen. Inorganic Chemicals Industry, 2012.

46 Z. Zhou, W. Qin, S. Liang, Y. Tan, and W. Fei. Industrial \& Engineering Chemistry Research, 2012, 51, 12926-12932.

47 S. Dong, L. Jinfeng, Z. Bo, N. Feng, Z. Zhongmin, and L. Lijuan. Journal of Salt Lake Research, 2013, 21, 51-57.

48 C. Shi, Y. Jia, C. Zhang, H. Liu, and Y. Jing. Fusion Engineering and Design, 2015, 90, 1-6.

49 Q. Xu. Chinese Journal of Organic Chemistry, 197913-33.

50 H.-f. Li, L.-j. Li, D. Shi, J.-f. Li, L.-m. Ji, X.-w. Peng, F. Nie, F.-g. Song, and Z.-m. Zeng. Hydrometallurgy, 2016, 160, 1-5. 
51 A.J.B. Kemperman, B. Damink, T. Van Den Boomgaard, and H. Strathmann. Journal of Applied Polymer Science, 1996, 65, 1205-1216.

52 A.K. Pabby,A.M. Sastre. Journal of Membrane Science, 2013, 430, 263-303.

53 J. Song, X.-M. Li, Y. Zhang, Y. Yin, B. Zhao, C. Li, D. Kong, and T. He. Journal of Membrane Science, 2014, 471, 372-380.

54 C. Jiang, Y. Wang, Q. Wang, H. Feng, and T. Xu. Industrial \& Engineering Chemistry Research, 2014, 53, 6103-6112.

55 X. Liu, X. Chen, L. He, and Z. Zhao. Desalination, 2015, 376, 35-40.

56 Z. Zhao, X. Si, X. Liu, L. He, and X. Liang. Hydrometallurgy, 2013, 133, 75-83.

57 R. Trocoli, A. Battistel, and F. La Mantia. Chemistry-a European Journal, 2014, 20, 9888-9891.

58 M. Pasta, A. Battistel, and F. La Mantia. Energy \& Environmental Science, 2012, 5, 9487-9491.

59 N. Intaranont. J.mater.chem.a, 2014, 2, 6374-6377.

60 M.M. Thackeray, P.J. Johnson, L.A. de Picciotto, P.G. Bruce, and J.B. Goodenough. Materials Research Bulletin, 1984, 19, 179-187.

61 F. Marchini, D. Rubi, M. del Pozo, F.J. Williams, and E.J. Calvo. The Journal of Physical Chemistry C, 2016.

62 J. Lee, S.-H. Yu, C. Kim, Y.-E. Sung, and J. Yoon. Physical Chemistry Chemical Physics, 2013, 15, 7690-7695.

63 S. Kim, J. Lee, J.S. Kang, K. Jo, S. Kim, Y.-E. Sung, and J. Yoon. Chemosphere, 2015, 125, 50-56. 